\title{
EN TORNO A LAS PUNTUALIZACIONES SOBRE LA DATACIÓN DE DOCUMENTOS MEDIEVALES DE LA CATEDRAL DE ASTORGA
}

\author{
Santiago DOMÍNGUEZ SÁNCHEZ \\ Universidad de León
}

RESUMEN: En este artículo se hace una crítica, desde el punto de vista de la Diplomática y de la Cronología, a un artículo recientemente aparecido que pretende cambiar las fechas propuestas para diversos diplomas altomedievales de la catedral de Astorga por las profesoras Cavero Domínguez y Martín López en su libro Colección documental de la catedral de Astorga. I (646-1126).

PALABRAS CLAVE: Cronología, Obispado de Astorga, documentos medievales, Tumbo Negro.

ABSTRACT: This paper is a scientific criticism, from the point of view of the Diplomatics and the Chronology, of a recent article that try to change the dates of some medieval documents conserved in the cathedral of Astorga and studied previously by the teachers Cavero Domínguez and Martín López in their book Colección documental de la catedral de Astorga. I. (646-1126).

KEYWORDS: Chronology, Bishopric of Astorga, medieval documents, Tumbo Negro.

En el año 1999, de la pluma de las Profesoras de la Universidad de León Gregoria Cavero Domínguez y Encarnación Martín López, dentro de la Colección "Fuentes y Estudios de Historia Leonesa", aparecía un excelente trabajo titulado Colección documental de la catedral de Astorga. I (646-1126), al que pronto, en el año 2000, seguía su continuación, Colección documental de la catedral de Astorga. II (1126-1299). En ambos libros se intentaba hacer, y, de hecho, se hacía, una reconstrucción de un archivo prácticamente desaparecido, el catedralicio astorgano, llegando a presentar al investigador o erudito interesado en estos temas mil quinientos catorce diplomas anteriores al año 1300.

De todos es sabido que el archivo de la catedral de Astorga sufrió diversos percances y accidentes a lo largo de la historia, y que el más grave fue el incencio del mismo en la Guerra de la Independencia. Efectivamente, había sido un archivo con riquísimos fondos medievales, pero casi desapareció a principios del siglo XIX. Hasta los años 1999 y 2000 los interesados en conocer los antiguos diplomas altomedievales de esa catedral se tenían que contentar con noticias sueltas y 
confusas dadas por los muchos investigadores que trabajaron sobre los mismos, especialmente la España Sagrada del padre Flórez o las diversas publicaciones de Augusto Quintana.

Quedaba pendiente una edición seria de esos diplomas, edición difícil, pero posible, puesto que de aquellos documentos desaparecidos ha quedado copia o noticia en códices y cartularios conservados hoy en diversos lugares: en la propia catedral de Astorga, en el Archivo Histórico Nacional, en la Biblioteca Nacional, en la Biblioteca del Palacio de Oriente o en la Real Academia de la Historia. También se sabía que había copias singulares o registros de algunos de estos diplomas en otros archivos, póngase por caso, el Vaticano.

Tal reconstitución del archivo catedralicio astorgano era una obra esperada muchas décadas por los historiadores del occidente hispano, y que nadie había tenido la osadía de realizar. La enorme dificultad del proyecto, que obligaba a trabajar con materiales de "segunda mano", difíciles e imprecisos, hizo que los lustros pasaran y nadie se atreviera a poner manos a la obra en este asunto.

Sin embargo, las doctoras Cavero y Martín emprendieron esta tarea con mucho ánimo, cargadas de paciencia, $\mathrm{y}$, según me consta, aun a sabiendas de que el resultado final de sus investigaciones nunca sería definitivo y podría ser cuestionado en muchos aspectos. Tras muchos años de trabajos, como decíamos, estos dos volúmenes vieron la luz. Las autoras del mismo han explicado claramente en la introducción a estos volúmenes la enorme complejidad de los diplomas en cuanto a su tradición documental y en cuanto a su cronología. La mayoría de los documentos sólo se conocen por copias o resúmenes hechos en los siglos XVIXVIII, y los autores de estos cartularios no supieron leer o interpretar correctamente lo que decían los originales: confundieron frecuentemente los numerales romanos "I" y "L", o "V" y "X"; no entendieron la llamada "X" aspada; no se dieron cuenta de que algunos diplomas aparentemente distintos eran un único texto, pero del que se conservaba un original y una copia posterior, quizá con fecha diferente; leyeron mal algunos de los nombres que aparecían en los sincronismos, etc.

Las profesoras Cavero y Martín avisaron en los referidos volúmenes que, tras mucho estudiar el asunto, habían decidido mantener en los regestos y transcripciones que ellas presentaban la fecha que aportan los cartularios consultados, aun sabiendo que podía ser errónea, si no había absoluta seguridad de la data exacta, y ello con la intención de no "inventar" ninguna data nueva que pudiera en un primer momento solucionar los problemas cronológicos presentados. Lógicamente, en esos casos, las citadas profesoras han dejado claro que la fecha es 
dudosa, o que otros autores que anterioremente habían tratado de ese diploma habían propuesto otra.

Tal decisión parece acertada. De todos es sabido que la Cronología técnica, disciplina que se enmarca dentro de la Diplomática y que estudia los problemas en torno a la fecha de los documentos, especialmente de los altomedievales, no recomienda plantear soluciones a la ligera. Es muy fácil decir que a un scriptor medieval se le olvidó añadir una o dos "C", o que un transcriptor de época moderna de textos medievales no supo interpretar una "X" aspada. Si no tenemos garantía de lo que ocurrió, es más prudente avisar de los problemas, y no dar como definitivas soluciones que pueden no serlo, o que no lo serían si tuviéramos más datos en la mano.

Con estas premisas se hicieron aquellos dos volúmenes. Efectivamente, como ya hemos explicado, partiendo casi de la nada (los documentos originales han desaparecido y las copias son poco de fiar), es imposible presentar una colección documental inmaculada.

En fin, explicado esto, diremos que en las páginas 275 a 302 de la Revista "Estudios humanísticos. Historia", número 3, del año 2004, apareció un artículo firmado por las profesoras Mercedes Durany Castrillo y $\mathrm{M}^{\mathrm{a}}$ Carmen Rodríguez González, con el título Puntualizaciones sobre la datación de algunos documentos de la catedral de Astorga del primer tercio del siglo XI: de Jimeno a Sampiro. En un primer momento me pareció que se trataba de un artículo posiblemente interesante. Sin embargo, una atenta lectura al mismo me llevó a pensar de forma distinta.

Según el Diccionario de la Real Academia de la Lengua, puntualizar es "Añadir una o más precisiones a algo con el fin de aclararlo, completarlo o corregirlo". ¿Realmente son puntualizaciones lo que han hecho las profesoras Durany y Rodríguez, o habría que denominar de otra forma a su artículo?

Personalmente, y dejando claro mi máximo respeto al trabajo de estas dos profesoras, dudo de que mucho de lo allí expuesto aclare, complete o corrija. Salvo en casos puntuales, no se aclaran grandes cosas, no se completa mucho más de lo que ya se decía en los volúmenes citados, y no se corrigen muchas datas, porque, de hecho, muchos casos difíciles son en gran medida incorregibles, al no ser posible con absoluta seguridad dar un fecha totalmente precisa.

Desde el Consejo de Redacción de esta Revista, "Estudios Humanísticos. Historia", por parte del que esto firma, se examinó el artículo presentado por las profesoras Durany y Rodríguez, y se les envió a las mismas unas líneas 
exponiéndoles que podían considerar o reconsiderar algunas de las afirmaciones allí realizadas, desde nuestro punto de vista más que cuestionables. Al no ser tenida en cuenta por su parte esta misiva, nos creemos en la obligación de hacer públicas algunas aclaraciones.

Trataré de explicarme a continuación. Antes diré que el que esto suscribe, de profesión paleógrafo y diplomatista, pensaba que ya había pasado a la historia la leyenda que versa sobre cierta propensión de determinados medievalistas a utilizar de continuo las colecciones documentales u otros trabajos de Diplomática, pero a condenarlos como acientíficos, faltos de mérito y escaparate o cúmulo de errores. Parecía ésta una leyenda de tiempos lejanos. Y, aunque seguramente es una leyenda falsa, o que sólo se debió aplicar a ciertos historiadores de poca categoría, no descartamos que todavía hoy tenga ciertos visos de realidad.

En primer lugar, no parece muy elegante utilizar una obra como ésta, la de las doctoras Cavero y Martín, y no dedicarle unas palabras o el más mínimo adjetivo. Aunque sea para después criticarla, parece caballeroso, al menos, añadirle el calificativo de "meritorio", o, al menos, "difícil" o "arduo" trabajo, y no despacharse con las palabras Hace ahora cinco años se publicó el primer volumen de las fuentes de la catedral a cargo de G. Cavero y E. Martín ..., y, más adelante, Esta obra será el punto de partida de nuestro trabajo... El lector del artículo de Durany-Rodríguez puede pensar que la obra que se va a criticar es un dechado continuo de errores, si no un ejemplo de vicios y maldades. Realmente, si de 1514 diplomas que estudiaron las profesoras Cavero y Martín se ponen ciertas pegas sólo a 29 , se podría haber dicho algo a favor de los demás.

El artículo de Durany-Rodríguez dedica sus diez primeras páginas a dos asuntos a los que, en mi opinión, no debería habérsele dedicado más de diez líneas. Concretamente, en esa especie de introducción se hace un repaso a las fuentes con las que habían contado las profesoras Cavero y Martín para su trabajo, algo que es repetir (y resumir) lo dicho por éstas en su trabajo. A continuación se da una relación de los obispos de la sede de Astorga en la primera mitad del siglo XI, que es exactamente igual a la publicada por esas mismas autoras, Durany y Rodríguez, en un artículo titulado El Obispado de Astorga en el primer tercio del siglo XI: de Jimeno a Sampiro, de reciente aparición en la revista Semata. Ciencias Sociais e Humanidades, núm. 15, del año 2003, págs. 187-222. ¿Por qué repetir en dos artículos lo mismo? ¿Acaso no se da por sentado que los estudios universitarios deben ser originales e inéditos?

En las páginas siguientes, Durany-Rodríguez pretenden demostrar que se deben modificar las fechas de 29 diplomas estudiados por las citadas profesoras de la 
Universidad de León. Algunas de esas propuestas pueden tener fundamento. Pero otras no lo tienen, y en otras sólo se puede hablar de nuevas hipótesis. Y lo que no puede hacerse es plantear como definitiva una nueva data que sólo es probable. Dicen textualmente Durany-Rodríguez: después del número de referencia se pone en primer lugar y en negrita la fecha correcta.

Veamos sólo algunos ejemplos significativos. En muchos casos la data presentada por las editoras de la Colección de Astorga tenía una nota explicativa de que había dudas sobre la misma, a la vez que se proponían o comentaban otras posibles fechas. Eso pasa ya en el primer diploma al que se quiere cambiar la fecha, que lleva el número 17 de la Colección Documental de Astorga, y en otros muchos, como el 193, el 233, el 246, el 249, el 274 o el 371. Que el diploma 244 es seguramente el mismo que el 303 ya lo habían dicho las doctoras Cavero-Martín.

La fecha del documento 168 la atrasan treinta años las profesoras DuranyRodríguez, aduciendo que entonces aparecen en otros documentos los intervinientes. Algo parecido sucede con el número 192, que se atrasa unos veinte años por razones creemos que no suficientemente fundadas, como la alusión a cierta rebelión o la presencia de un notario (mejor sería llamarle rogatario) en años posteriores. Sin embargo, parece obligado dar más razones o de más peso para modificar estas datas. Durany-Rodríguez plantean problemas, incluso, a la data de uno de los pocos diplomas originales que se conservan en la catedral de Astorga, número 254 de la Colección, por cierto, perfectamente transcrito.

Siguiendo los consejos de la Diplomática y de la Cronología técnica, no se debe acudir fácilmente a la "movilidad de fechas", porque ello lleva a rectificar repetidamente la datación de diplomas con fecha dudosa, cosa que, por ejemplo, hizo el referido Dr. Quintana en varias ocasiones (véase el documento 342 de la Colección). Además, debe tenerse en cuenta que el propio Tumbo de Astorga indica en varios casos que hay "instrumentos del mismo tenor, con fechas distintas", o que hay documentos con más de una redacción.

Por otro lado, Durany-Rodríguez explican que los diplomas 242 y 340 de Colección de Astorga son un único documento. Estudiando lo anotado por CaveroMartín, vemos que se trata de donaciones de un mismo matrimonio a un mismo monasterio. Del documento 242 se conserva el texto completo y del diploma 340 sólo un resumen. Con los datos aportados por ambas fuentes se puede concluir claramente que se trata de dos documentos distintos, y no de un mismo diploma que se ha duplicado. No es extraño en absoluto que, en esta época, haya dos o más donaciones del mismo autor al mismo destinatario. Algo similar es posible que pase en los documentos 287 y 288 de esta Colección. 
En otros casos las puntualizaciones cronológicas no son tales, sino que sólo se hacen matizaciones de otro tipo. Los documentos 172, 247 ó 251 se critican sólo para decir que a las editoras leonesas se les había olvidado anotar algún dato o los sincronismos; o los documentos número 248 y 256 se ponen en entredicho para decir únicamente que no se había indicado que en una de las copias aparecía como obispo de Astorga Alfonso, y que luego ese nombre se había tachado.

Pero hay más. Se dice como novedad que el documento 169 es el mismo que el 177, pero esta posibilidad ya la habían señalado las profesoras Cavero-Martín. Algo parecido sucede en el comentario al documento número 180 de la Colección de Astorga. Fechado por Cavero-Martín en el 996, aunque indicando que otros autores lo habían datado en el 986, Durany-Rodríguez lo fechan en este último año, criticando a las primeras y callando que aquéllas ya habían hablado de esta posibilidad. Exactamente lo mismo pasa con el documento 262 de la Colección, fechado por Cavero-Martín en 1030, y por Durany-Rodríguez en 1010, sin decir que esta segunda fecha, que copia el Tumbo Negro, también la citan las primeras. Estas omisiones u ocultaciones no parecen propias de un trabajo cientítico.

En fin, espero que lo expuesto valga para comprender que un trabajo como el realizado por las profesoras leonesas es extraordinariamente arduo y difícil de llevar a cabo. También deseo que lo relatado aquí sirva para que el lector de este artículo juzgue los hechos, estudie detenidamente los volúmenes de las doctoras Cavero y Martín, analice también el comentario de las doctoras Durany y Rodríguez, y y se forme su propia opinión. 